Pinho, T.R.R.; Santos, A.J.C. Passivos socioambientais oriundos de empreendimentos turísticohoteleiros e seus impactos na base comunitária. Revista Brasileira de Ecoturismo, São Paulo, v.6, n.1, jan/abr-2013, pp.297-312.

\title{
Passivos socioambientais oriundos de empreendimentos turístico-hoteleiros e seus impactos diretos na base comunitária
}

\author{
Social and environmental liabilities generated by the enterprises of \\ tourist's hotels and their direct impact on the community-based
}

\section{Thays Regina Rodrigues Pinho, Ana Jéssica Corrêa Santos}

\begin{abstract}
RESUMO:
A pesquisa em questão tem por objetivo identificar e avaliar os passivos socioambientais gerados pela instalação e operação do Complexo Turístico Enseada de Suape, situado na zona costeira de Pernambuco. Os passivos oriundos do empreendimento turístico-hoteleiro representam um aspecto limitante do processo de licenciamento ambiental. Teve-se como referência a análise do seu Estudo de Impacto Ambiental (EIA) frente ao parecer técnico do órgão estadual de meio ambiente, contrapondo-se à observações feitas na área. Com uma abordagem qualitativa e crítica, realizou-se um estudo exploratório, com o emprego das seguintes técnicas investigativas: pesquisas bibliográficas, documentais e iconográficas e pesquisas de campo, com aplicação de entrevistas semiestruturadas, junto a representantes da iniciativa privada, poder público competente e comunidade local, e observações sistemáticas in loco. A construção do empreendimento acarretou impactos econômicos positivos, como a geração de renda e emprego, entretanto, os passivos socioambientais associados a ele são mais relevantes, tais como: degradação dos ecossistemas, deslocamento populacional, rupturas na sociabilidade e mudança nos modos de vida da comunidade. Os empreendedores priorizaram os benefícios econômicos em relação aos aspectos ambientais e sociais e não planejaram ações social e ambientalmente responsáveis para o entorno.
\end{abstract}

PALAVRAS-CHAVE: Passivos Socioambientais; Base Comunitária; Estudos de Impacto Ambiental; Licenciamento Ambiental.

\begin{abstract}
:
The research project aims to identify and assess the social and environmental liabilities generated by the installation and operation of the Complexo Turístico Enseada do Suape, located on the coast of Pernambuco, Brazil. The liabilities arising from the tourist-hotel represent a limiting aspect of the licensing process. Took as reference the analysis of its Environmental Impact Assessment (EIA) against the technical opinion of the state environmental agency, in contrast to the observations made in the area. With a qualitative approach and criticism, there was an exploratory study with the use of the following investigative techniques: bibliographic, iconographic and documentary and field research, with application of semi-structured interviews, with representatives from the private sector, government authority and the local community, and systematic observations on the spot. The construction of the project brought positive economic impacts, such as income generation and employment, however, social and environmental liabilities associated with it are more relevant, such as environmental degradation, population displacement, disruptions in sociability and changing lifestyles of the community. The entrepreneurs have prioritized economic benefits in relation to environmental and social aspects, not planned actions socially and environmentally responsible to the environment.
\end{abstract}

KEYWORDS: Social and environmental liabilities; community-based, environmental impact studies, environmental licensing. 
Passivos socioambientais oriundos de empreendimentos turístico-hoteleiros e seus impactos na base comunitária

\section{Introdução}

Os impactos ambientais associados ao turismo trazem consequências adversas para o meio ambiente, quando não existe um planejamento adequado. Os equipamentos turístico-hoteleiros vêm crescendo em número, principalmente, na zona litorânea do Nordeste brasileiro, reconhecido pela exuberância de suas paisagens naturais. A quantidade incessante de empreendimentos que surgem ao longo dos anos merece atenção especial, a fim de que não prejudiquem a diversidade ecológica.

É preciso reavaliar os aspectos econômicos associados a instalação dos empreendimentos, que preveem a geração de benefícios econômicos para população inserida próxima a eles, aos empreendedores e ao poder público, mas que não refletem de modo mais amplo sobre as consequências para o ambiente em que se instalam.

Os passivos socioambientais representam os danos causados ao meio ambiente e ao espaço comunitário de determinado local, o que simboliza a obrigação e a responsabilidade social da empresa perante os aspectos socioambientais. A identificação do passivo socioambiental revela a responsabilidade e obrigação da restauração ambiental pelas empresas, o que, na prática, nem sempre ocorre. Por isso os passivos socioambientais são elementos primordiais nas negociações entre empresas, fusões e privatizações, uma vez que os custos podem recair sobre os novos proprietários. Passam a ser um fator decisório, pois permite avaliar e quantificar os custos e gastos potenciais para sanar as questões socioambientais a curto, médio e longo prazo.

$\mathrm{Na}$ atividade turística, a aplicação dos conceitos relativos aos passivos socioambientais é recente, mas é necessário incorporar tal medida a fim de que os empreendimentos conheçam suas responsabilidades e obrigações e possam discriminar as ações e esforços desenvolvidos para a eliminação ou redução de danos socioambientais.

O presente estudo objetiva identificar e avaliar os passivos socioambientais decorrentes da instalação e operação do Complexo Turístico Enseada de Suape, situado na zona costeira de Pernambuco. Pode-se afirmar que os passivos oriundos do empreendimento turístico-hoteleiro representam um aspecto limitante do processo de licenciamento ambiental, uma vez que não se estabeleceu no estudo de impacto ambiental do empreendimento as medidas para restauração e responsabilidades quanto às obrigações socioambientais geradas.

Trata-se de estudo exploratório com uma abordagem qualitativa e crítica, e com o emprego das seguintes técnicas investigativas: pesquisas bibliográficas, documentais e iconográficas e pesquisas de campo, com aplicação de entrevistas semiestruturadas, junto a representantes do poder público, iniciativa privada e comunidade local, e observações sistemáticas in loco. 


\section{Impactos socioambientais ocasionados por empreendimentos turístico- hoteleiros}

Os impactos do turismo dizem respeito ao conjunto de modificações decorrentes do desenvolvimento turístico nos destinos receptores. Atingem diferentes esferas (ambiental, social, econômica, cultural etc.) e podem ser positivos ou negativos. Os impactos ambientais negativos afetam a qualidade ambiental das localidades e sua atratividade turística.

A construção e o funcionamento de equipamentos turísticos e hoteleiros implicam em impactos ambientais negativos diversos, tais como: destruição de ecossistemas, descaracterização da paisagem local, deslocamento da população de seu local de residência, consumo de recursos naturais, dentre outros.

A geração de resíduos sólidos, a exemplo de: embalagens vazias, restos de comidas e de produtos de limpeza; a geração de efluentes líquidos com a destinação final do esgoto e águas utilizadas pelos equipamentos, se não tratados adequadamente, afetam mananciais e praias; a emissão de gases e ruídos por veículos, máquinas, chaminés etc; e a poluição visual decorrente de construções não integradas ao ambiente, são questões que contribuem para agredir o meio ambiente.

No caso do turismo, estas agressões ocorrem com elevado impacto durante a construção dos empreendimentos. A poluição gerada no período de sua operação pode e deve ser controlada. A compostagem de material orgânico, o tratamento dos efluentes líquidos, o reuso da água, a reciclagem de materiais são formas de controlar a poluição ambiental, que podem ser implantadas nas empresas turísticas.

Em áreas com industrialização acentuada, a instalação de hotéis e pousadas não simboliza um impacto ambiental com alto grau poluidor, tendo em vista que outras atividades industriais são responsáveis por danos maiores, a exemplo das indústrias químicas, petroquímicas, metalúrgicas, de papel e celulose e de extração e tratamento de minerais. Entretanto, merece atenção a gestão adequada dos mesmos para que não contribuam com o aumento da poluição ambiental nas grandes cidades, onde a qualidade do ar, da água e do solo encontra-se, na maioria dos casos, comprometida.

O impacto ambiental é definido como:

[...] qualquer alteração das propriedades físicas, químicas e biológicas do meio ambiente, causada por qualquer forma de matéria ou energia resultante das atividades humanas que, direta ou indiretamente, afetam: a saúde, a segurança e o bem-estar da população; as atividades sociais e econômicas; a biota; as condições estéticas e sanitárias do meio ambiente; a qualidade dos recursos ambientais (BRASIL, RESOLUÇÃO CONAMA 001, 1986, p. 01).

Como afirma Abreu (2001, p. 13): 
Como os hotéis utilizam os recursos naturais, que são também utilizados por qualquer empresa e todos os indivíduos, a utilização desses recursos, tais como a água, alimentos, por exemplo, representa um impacto ambiental significativo. Assim, a idéia de que hotéis não causam impactos ao meio ambiente trata-se de uma visão distorcida da realidade. Sem mencionar os impactos ambientais decorrentes do lixo que é gerado nestes locais, dos equipamentos e produtos de uso diário que agridem o meio ambiente, dos efluentes líquidos, que são lançados em rios e mares misturados com detergentes e outros dejetos orgânicos, e tantas [sic] outros aspectos.

Um fator de preocupação é a localização dos equipamentos turístico-hoteleiros, muitas vezes, situados em áreas com significativa fragilidade ecológica. E, por isso, merecem o devido cuidado com a instalação e operação. Em termos de controle ambiental, o poder público criou mecanismos para avaliar os impactos de grandes complexos turísticos, obrigando-os ao licenciamento ambiental ${ }^{1}$. Para ser licenciado é preciso que o empreendimento realize a Avaliação de Impactos Ambientais (AIA), que descreverá as possíveis alterações que causará no meio ambiente.

Se por um lado, o turismo traz dividendos e desenvolvimento econômico, por outro lado, constata-se que o turismo de massa e o superdimensionamento dos equipamentos receptivos são altamente predatórios e impactam agressivamente as comunidades receptoras a nível sociocultural.

[...] a qualidade de uma destinação turística vem sendo avaliada com base na originalidade de suas atrações ambientais. A questão fundamental nesse caso é a premente necessidade de controlar o crescimento quantitativo dos fluxos turísticos, uma vez que os ecossistemas sensíveis ficam comprometidos quando ultrapassam os limites de sua capacidade de carga (COUTINHO, 2000, p. 05)

Isto, especialmente em áreas litorâneas, que recebem intenso fluxo de visitantes, pelo poder de atratividade que exercem nos turistas e, consequentemente, nos empresários, que promovem volumosos investimentos em equipamentos turísticohoteleiros.

Os atrativos de determinada localidade, tanto os naturais quanto os culturais, fazem parte da atratividade que o local (destino turístico) exerce sobre a escolha dos turistas. Quando existe degradação ambiental, torna-se o destino turístico esvaziado e os empreendimentos, ali, instalados entrarão em declínio por falta de clientela. Logo, o turismo e suas atividades correlatas, como a hotelaria, dependem da manutenção do equilíbrio ambiental.

Ao se pensar em equilíbrio ambiental dentro da atividade turística, almeja-se a prática do turismo sustentável, com o exercício de ações responsáveis perante a natureza. De acordo com a OMT, o turismo sustentável é aquele que atende às necessidades dos turistas, hoje, e dos destinos receptores, ou seja, locais que recebem os turistas, ao mesmo tempo em que protege e amplia as oportunidades para o futuro, 
mantendo os benefícios que a atividade oferece durante os anos que virão. Swarbrooke (2000) o define como um turismo economicamente viável, que não destrói os recursos dos quais dependerá no futuro, principalmente o meio ambiente e o social. Embora estudiosos da área venham formulando conceitos e planejando ações que envolvem o turismo sustentável, o desafio ainda persiste em encontrar o equilíbrio entre desenvolvimento turístico e conservação ambiental.

Os instrumentos utilizados no processo de licenciamento ambiental, a exemplo do Estudo de Impacto Ambiental (EIA) e seu respectivo Relatório de Impacto Ambiental (RIMA), vêm auxiliando na prevenção dos riscos ambientais associados ao turismo, pois avaliam os impactos futuros da atividade antes de sua implantação e propõem medidas de mitigação e compensação para os impactos previstos.

\section{Passivos socioambientais e sua ocorrência na atividade turística}

$\mathrm{Na}$ linguagem contabilista o passivo é o endividamento do agente investidor, que pode ser de curto prazo, como contas de energia, água, impostos, e de longo prazo, como os empréstimos bancários e financiamentos (JERONYMO, 2007)

Passivo socioambiental é o débito ou custo socioambiental de um empreendimento provocado pela parcela da degradação socioambiental não recuperada. Como afirma Jeronymo (2007, p. 67) "[...] o passivo é um custo e seu responsável deverá assumir a responsabilidade pelo custo negativo produzido".

O significado do termo passivo refere-se a ocorrência de danos cuja responsabilidade é do agente que promove alterações no ambiente ou na estrutura social, no espaço onde se almeja instalar determinado processo produtivo ou já esteja operando e produzindo.

Averigua-se que os exemplos de passivos socioambientais decorrentes de outras atividades produtivas, citados por Jeronymo (2007) e Carneiro (2008), podem ser percebidos setor turístico. Alguns tipos de passivos socioambientais possíveis de ocorrer em construções de empreendimentos turísticos são: erosão; solos expostos; inundação de áreas adjacentes; assoreamento de cursos d'água; poluição visual; conflitos com a população local; degradação de ecossistemas; conflito com passagem de animais silvestres; deslocamentos populacionais compulsórios; mudanças bruscas nos hábitos e modos de vida; desgaste ou perda dos valores culturais; corrosão, desgaste ou perda dos valores intrínsecos as relações de sociabilidade local.

A preocupação quanto à reparação dos danos ocasionados pela atividade turística é expressa na Lei 11.771/2008, que em seu artigo 6으 coloca que o Plano Nacional de Turismo - PNT será elaborado pelo Ministério do Turismo, ouvidos os segmentos públicos e privados interessados, com o intuito de promover, dentre outros: a atenuação de passivos socioambientais eventualmente provocados pela atividade turística.

Outro exemplo que reforça a problemática dos passivos socioambientais na atividade turística é representado pelo PRODETUR/NE, programa de crédito para o po- 
Passivos socioambientais oriundos de empreendimentos turístico-hoteleiros e seus impactos na base comunitária

der público estadual e municipal, com o intuito de melhorar e expandir o turismo e promover melhorias na qualidade de vida das populações.

Na primeira fase, os projetos prioritários estiveram aliados à conservação ambiental, visto que os recursos naturais constituem a matéria-prima principal do turismo, na região, localizados, em sua maior parte, na zona costeira. Porém, conforme avaliação posterior percebeu-se que o foco ambiental, em alguns casos, não foi atingido. Diversas obras realizadas comprometeram a qualidade ambiental, com geração de passivos socioambientais.

Após a conclusão do PRODETUR/NE I, foi realizada uma avaliação com o intuito de identificar as falhas e pontos positivos para promover melhorias na etapa posterior. A avaliação demonstrou falhas associadas, principalmente, às obras de transporte viário e de saneamento. Outros problemas identificados foram: a ocorrência de impactos ambientais e sociais negativos, devido a análises limitadas na construção de estradas e estações de tratamento de água e esgoto sanitário; a falta de monitoramento ambiental pelos órgãos competentes e a falta de cumprimento das medidas mitigadoras pelos empreiteiros; a ocupação inadequada e desordenada da faixa costeira, devido à falta de instrumentos de ordenamento; e problemas na implantação de unidades de conservação e na finalização de seus planos de manejo.

A experiência da primeira fase acarretou alterações nas estratégias de ação e adoção de novos conceitos. Foi incorporado o conceito de pólos turísticos e o seu desenvolvimento através do planejamento participativo, integrado e sustentável, com ações que beneficiem a população local, que procurem mitigar os passivos socioambientais associados ao PRODETUR/NE I, que complementem e completem os investimentos da primeira fase e fortaleçam a gestão municipal (BNB, 2006).

\section{Ações ambientais para o desenvolvimento do setor turístico-hoteleiro: exigên- cias legais e da sociedade}

É possível fazer com que a atividade turística cresça e se desenvolva sem que, para isso, tenha que degradar o meio ambiente. Na utilização racional dos recursos, o poder público é responsável em exigir e fiscalizar o cumprimento das leis ambientais. Em paralelo, a sociedade civil necessita estar consciente de seu papel na proteção ambiental.

Segundo Kirk (1996), a questão ambiental afeta diversos segmentos sociais desde os anos 80 e 90, estando incluído o setor de hospedagem. Uma atenção maior era dada aos setores que causavam danos diretos ao meio ambiente e que geravam maior índice de poluição na saída do processo, geralmente, da produção industrial. Hoje, o foco é mais abrangente e procura-se minimizar os impactos da operação por completo, seja na produção industrial ou no setor de serviços e setor primário.

Diante de uma visão pró-ativa da sociedade, que incorporou os valores ambientais como aspectos cruciais dentro do seu processo de decisão e escolha, cobra-se dos setores empresariais uma postura semelhante, que ofereça, além da qualidade na prestação dos serviços e produtos, uma postura que conserve os recursos natu- 
rais. Essa condição levou turistas do mundo inteiro a cobrarem do setor turístico, desde os anos de 1990, a adoção de medidas que minimizassem seus impactos ambientais.

Em resposta, o setor hoteleiro publicou, em 1995, o Pacote de Ações Ambientais para Hotéis - conjunto de ações práticas para beneficiar o seu negócio e o meio ambiente, produzido pela Associação Internacional de Hotéis, a Iniciativa Ambiental de Hotéis Internacionais e o Programa Ambiental das Nações Unidas. Neste pacote, recomenda-se a adoção de ações que garantam a sustentabilidade da atividade turística em longo prazo. Para isso, é preciso minimizar o desperdício e reduzir, reutilizar e reciclar os produtos consumidos (COSTA, 2004).

As ações propostas permeiam as áreas de energia, resíduos sólidos, água, efluentes, emissões, controle de fornecedores e assuntos gerais. Nos dias atuais, grupos consolidados no setor de hospitalidade empregam seus próprios programas de ações ambientais. A Rede Accor, referência mundial, apresentou recentemente seu programa de sustentabilidade, Planet 21, que abrange todos os seus hotéis e clientes. Ao todo, são 21 compromissos e objetivos adotados, dentre eles estão a redução do consumo de água, em 15\% e de energia, em 10\%. A rede pretende promover a utilização de produtos ecológicos em 85\% dos hotéis (PEGADAS ECOLÓGICAS, 2012).

Os turistas, por sua vez, inseridos nesta sociedade e impelidos a adotar uma postura ética frente ao meio ambiente, passam a cobrar medidas responsáveis das empresas ligadas ao setor, incluindo aí os meios de hospedagem. É, dessa forma, que são incorporadas metas ambientais para manter a qualidade do meio ambiente, no intuito de garantirem seu crescimento no mercado ao longo dos anos.

A indústria do turismo em geral e o setor hoteleiro em particular, deve ter sua parcela de responsabilidade em fazer da ética e do desenvolvimento sustentável, partes integrantes de suas metas, já que dependem da qualidade do meio ambiente para o seu crescimento (FERREIRA, 1999, p. 03).

Os novos rumos que a gestão turística vem seguindo, ainda que lentamente, estão baseados na redução dos seus impactos, com a incorporação de aspectos socioambientais. Este fato traz mudanças ao comportamento dos gestores hoteleiros, à medida que, mais conscientes de sua responsabilidade perante a sociedade, atuam para garantir melhores resultados econômicos, sociais e ambientais. A adoção da AIA e elaboração do EIA como instrumentos que colaboram para o adequado gerenciamento ambiental, antes mesmo da implantação e operação dos empreendimentos, pode ser uma opção sustentável e acertada para os futuros empreendedores do setor hoteleiro.

\section{O EIA e a participação comunitária na gestão de empreendimentos do setor}

Desde a década de 1970, começou-se a elaborar EIAs, no Brasil, em cumprimento às exigências do Banco Mundial, especialmente em projetos de construção de 
Passivos socioambientais oriundos de empreendimentos turístico-hoteleiros e seus impactos na base comunitária

usinas hidrelétricas (ROCHA et al., 2005). Pouco depois, o governo brasileiro instituiu por força de lei a obrigatoriedade do estudo de impacto ambiental para atividades que causam impactos ambientais significativos.

Segundo as diretrizes definidas na Resolução CONAMA no 001/86, para a elaboração do EIA é exigido que se faça o diagnóstico ambiental da área; a descrição da ação proposta, com identificação de alternativas tecnológicas e de localização do projeto, verificando a hipótese de não implantação do mesmo; a identificação, análise e previsão dos impactos significativos nas fases de implantação e operação; definir as áreas de influência direta e indireta; e analisar a compatibilidade com os planos e programas governamentais propostos e em implantação na área de influência.

A audiência pública é um dos procedimentos que vem sendo utilizado para incluir a base comunitária no processo de licenciamento ambiental. Prevista por lei, mas de caráter não obrigatório, deve ser solicitada no prazo de 45 dias após o recebimento do EIA/RIMA pelo órgão competente de meio ambiente, quando este julgar ser necessário ou quando requerida por entidade civil, pelo MP ou por um número igual ou superior a 50 cidadãos.

O objetivo da audiência é apresentar à comunidade a ação ou atividade proposta e os respectivos impactos decorrentes da sua implantação. A partir daí, são feitos questionamentos e coletadas criticas e sugestões que influenciarão no parecer final dado pelo órgão (IBAMA, 1995)

Entretanto, a audiência pública não tem demonstrado ser eficiente no processo de tomada de decisão e novas formas de inserir a base comunitária vêm sendo pensadas. Dessa forma, será possível obter soluções compartilhadas sobre os efeitos negativos do empreendimento por todos os atores sociais envolvidos com o licenciamento, os quais serão afetados pelas ações a serem implantadas, além de possibilitar o crescimento do senso de responsabilidade no acompanhamento e monitoramento dos impactos ocorridos.

Alguns problemas evidenciados na elaboração dos EIA/RIMAs que fogem ao que a legislação especifica dizem respeito a: relação de dependência da equipe multidisciplinar com o empreendedor, contratada por ele; dificuldade em delimitar a área de influência do projeto de acordo com os efeitos ambientais; as equipes tendem a defender o projeto, sem descrever as alternativas tecnológicas e de localização, inclusive de não implantação; desconhecimento de métodos adequados de avaliação de impacto ambiental; proposição de medidas mitigadoras incoerentes com os impactos gerados; e apresentação de RIMA sem clareza de compreensão para o público em geral.

$\mathrm{Na}$ atualidade, a conduta empresarial deve rumar em prol de uma cultura conservacionista, que passa a ser exigida, a partir das evidências de progressiva degradação dos recursos naturais ao longo da história, concorrendo para o comprometimento da sobrevivência da espécie humana no planeta. Uma dessas condutas é o gerenciamento ambiental dos negócios com a incorporação de seus diversos instrumentos. 
A gestão ambiental, conforme coloca Barbieri (2004, p. 20), pode ser entendida como:

as diretrizes e as atividades administrativas e operacionais, tais como planejamento, direção, controle, alocação de recursos e outras realizadas com o objetivo de obter efeitos positivos sobre o meio ambiente, quer reduzindo ou eliminando os danos ou problemas causados pelas ações humanas, quer evitando que eles surjam.

Alguns autores tratam a gestão ambiental como a gestão de sustentabilidade, o que significa a avaliação da capacidade de resposta do ambiente aos resultados dos processos produtivos que nele são realizados e que o afetam, através da monitoração sistemática da qualidade do ar, da água, do solo, da flora, da fauna e do ser humano.

Os estudos ambientais contribuem para o gerenciamento ambiental das empresas turístico-hoteleiras ao reforçarem as características ambientais gerais da área onde estão inseridas e ao indicarem os elementos suscetíveis aos impactos de acordo com cada atividade a ser realizada. Antes mesmo de sua instalação, é possível controlar os aspectos ambientais e planejar as ações, mediante as estimativas traçadas pelos estudos.

O conteúdo apresentado nos estudos ambientais oferece informações detalhadas e importantes sobre o local em que se instalará determinado equipamento hoteleiro, ideais para um planejamento gerencial em curto, médio e longo prazo. Neste sentido, o uso planejado dos espaços turísticos contribui para a preservação do patrimônio natural e a utilização do EIA como uma ferramenta própria da gestão ambiental pode garantir a prática da atividade turística de modo responsável. É, portanto, um instrumento eficaz para dar suporte aos empreendedores quanto ao planejamento de suas ações.

\section{Pontos de conflitos do Complexo Turístico Enseada de Suape}

O Complexo Turístico Enseada de Suape é caracterizado como um empreendimento de grande porte, instalado em área de relevância ambiental e proposto por empreendedores da iniciativa privada. O EIA, referente ao equipamento, foi entregue a Agência Estadual de Meio Ambiente e Recursos Hídricos (CPRH), em dezembro/90 e a audiência pública foi realizada em dezembro/91, no Cabo de Santo Agostinho. Os documentos do órgão licenciador reiteram a sua aprovação e a obtenção da licença ambiental.

Os proponentes reforçaram repetidas vezes, no projeto do complexo turístico, suas preocupações com a preservação ambiental e com o patrimônio históricocultural do local. O EIA, documento que avaliou os impactos decorrentes de sua instalação, confirmou a intenção: "a implantação de um Complexo Turístico desse porte numa área de valor histórico e paisagístico levou os seus idealizadores a estabelecerem, como premissas básicas, a preservação da natureza e da cultura local' (PIRES FILHO, 1990, p. 13). 
Passivos socioambientais oriundos de empreendimentos turístico-hoteleiros e seus impactos na base comunitária

Entretanto, diversos pontos falhos foram identificados no projeto. Segundo expõe Pires Filho (1990, p. 12), "[...] embora não contando com os projetos específicos, o empreendedor propõe em poucas linhas a melhor infraestrutura básica possivel para suprir as necessidades para o perfeito funcionamento do projeto". Mas não especificou como seria a condução destes projetos, como seriam implantados e o que estava previsto nos mesmos. Outras questões foram vagamente descritas, tal como a técnica utilizada na Estação de Tratamento dos Efluentes (ETE).

As questões polêmicas trataram notadamente da retirada e aterro da vegetação de mangue para a construção dos equipamentos e da retirada da população residente da área. O processo de aterramento em execução na área, no inicio dos anos 1990, alterou a configuração paisagística da praia de Suape. Contornando a situação, a equipe multidisciplinar responsável pelo EIA atestou que a vegetação do local encontrava-se bastante antropizada, exceto determinadas áreas do manguezal estuarino de Suape.

Conforme os relatos, o pontal de Suape, no qual se situa o hotel, sofria grave e irreversível processo erosivo marinho e o manguezal, ali presente, corria sério risco de extinção natural. É certo que o impacto maior ao ecossistema foi na fase de implantação do empreendimento. Os efeitos adversos foram reduzidos, na fase de operação, mas ainda são perceptíveis ações antrópicas sobre o ecossistema.

A retirada do manguezal foi compensada com o replantio de 6 ha de vegetação de mangue, no próprio estuário do Rio Massangana. Como informam Castelo Branco e Spinelli (2004), em contrapartida ao desmatamento, plantou-se mangue em local distante do empreendimento, próximo à uma empresa fabricante de barcos, localizada no interior do estuário.

Sabe-se que os ambientes, ao entrarem em desequilíbrio, tendem naturalmente para um ajuste (o equilíbrio dinâmico), em cada nova situação criada. A situação criada com a instalação do empreendimento hoteleiro provocou alterações permanentes ao meio ambiente, que devem ser observadas e avaliadas de perto.

$\mathrm{O}$ projeto apresentado à $\mathrm{CPRH}$ não foi realizado na íntegra devido, principalmente, a inviabilidade econômica apresentada por estudos de mercado, que constatou possível carência de demanda turística para empreendimentos de mega porte (CASTELO BRANCO; SPINELLI, 2004). Outro aspecto que pode ter interferido adversamente foi sua proximidade do Porto de Suape.

Da proposta inicial, que vislumbrava a construção de inúmeras edificações para fins de veraneio, turismo e prática de lazer, os equipamentos construídos, até a presente data, são o hotel, o restaurante e alguns equipamentos destinados à prática dos esportes náuticos, como o ancoradouro para pequenas embarcações. Com um total de 300 apartamentos, possui ETE própria, restaurante, centro de ginástica, boate, piscina, quadras esportivas e centro de convenções. 


\section{Impactos positivos associados ao empreendimento}

Em termos de impactos positivos, o empreendimento gerou benefícios econômicos significativos, com incrementos na renda, dinamização da economia no distrito do Cabo de Santo Agostinho e ampliação da oferta de empregos formais e informais. Comprova-se também a melhoria promovida na infraestrutura local, com vias de acesso asfaltadas, áreas de lazer construídas (Praça da Vila) e maior oferta de transporte público, na Vila de Suape.

Outro ponto positivo foi a recomposição da faixa de praia através do sistema de dragagens. A praia havia sido alterada em sua fisionomia por processo erosivo, a partir das intervenções feitas pelo CIPS, as quais acarretaram alterações na dinâmica costeira, provocando grave erosão marinha com redução da faixa da praia, derrubada da vegetação e das casas de pescadores, ali, existentes (PIRES FILHO, 1990).

Constata-se a recente valorização dos recursos naturais do local (praia, mangues, rios) pelos moradores, o que contribui para sua conservação e sua utilização para o lazer e recreação. Este fato ocorreu a partir da mudança de comportamento dos turistas frente à natureza, que procuram respeitá-la e conservá-la. A população local passou a adotar semelhante postura, o que representa um efeito benéfico.

A instalação do resort incrementou a atividade turística na localidade, gerando um significativo aumento no fluxo de turistas, veranistas e excursionistas na praia. Diversos fatores contribuíram para isso, o engordamento da praia que a deixou paisagisticamente mais atrativa, as melhorias nas vias de acesso e a crescente divulgação do local.

\section{Passivos socioambientais oriundos do empreendimento}

Em termos socioeconômicos, as mudanças na comunidade local, em destaque na Vila de Suape, ocorrem desde a instalação do Complexo Industrial-Portuário de Suape (CIPS) e se agravaram com a instalação do empreendimento hoteleiro de padrão internacional. A vila sofreu um crescimento populacional devido à construção do porto, quando as famílias que viviam no terreno destinado ao complexo foram ali realocadas.

A sua dinâmica de transformação apresenta peculiaridades marcadas por aspectos externos e não internos. As intervenções feitas pelo CIPS e equipamento hoteleiro partiram de investidores externos e não da população local. Este fato pode indicar que os moradores locais se mantêm à margem do processo decisivo das questões econômicas, tão importantes para o desenvolvimento local, seja por comodismo, falta de organização social ou por forças políticas externas.

O processo de expropriação das famílias do terreno pertencente ao empreendimento turístico-hoteleiro ocorreu em 1988, muito antes da apresentação do EIA a CP$\mathrm{RH}$ e da obtenção de licença ambiental para sua construção. Dessa forma, os impactos ambientais relativos ao equipamento já estavam presentes, ao menos quanto ao meio antrópico.

Como forma de compensação ambiental, 29 famílias de pescadores passaram 
Passivos socioambientais oriundos de empreendimentos turístico-hoteleiros e seus impactos na base comunitária

a habitar uma pequena vila situada na entrada do empreendimento, em casas construídas pela Ipojuca Empreendimentos e Participações S/A. A título de indenização outras casas, 07 no total, foram entregues aos veranistas e a um pescador, em época posterior (1997), com melhores condições de moradia e conforto e localizadas na beira-mar.

A construção do complexo turístico gerou grandes expectativas de melhorias sociais na comunidade, que viam com bons olhos o incremento de novos postos de trabalho, com novas oportunidades de empregos para a população praieira. Houve um rearranjo estrutural da localidade com a introdução do equipamento, o que levou a modificações, principalmente, na forma de moradia, passando de casas de taipa para casas de alvenaria, e na produção de renda, antes atrelada a atividade pesqueira e agora à atividade turística.

Tendo em vista que os empregos formais exigem maior capacitação, o baixo nível de escolaridade da comunidade implica no reduzido número de empregos fornecidos, além da política adotada de empregar apenas um membro de cada família. O número de empregos oferecidos, em 2004, era de 345 , muito abaixo do pretendido no projeto e reiterado pelo EIA, que previam um total de 1.000 empregos diretos. Segundo Castelo Branco e Spinelli (2004) do total, 222 eram residentes do Município de Cabo de Santo Agostinho, sendo 46 residentes da Vila de Suape.

Agravam a situação a sazonalidade, em que a demanda por mão de obra fica reduzida nas épocas de baixa estação e empregos poucos atrativos, com longas jornadas de trabalho e remuneração baixa. Os empregos informais, por outro lado, aumentaram, em especial, os associados ao comércio de alimentação e artesanato. Estes dados, coletados em pesquisa realizada em 2004, alertaram a comunidade sobre a importância da formação escolar e profissional, instigando-a a buscar o conhecimento e a educação.

O modelo de empreendimento adotado, hotel tipo resort, não promove o contato efetivo entre turistas e comunidade local, a fim de que os hóspedes possam conhecer e entender a dinâmica cultural e social da comunidade. Pois, de acordo com seus objetivos, o resort oferece diversos tipos de serviços, lazer e produtos a fim de entreter seus hóspedes o maior tempo possível em suas instalações. O turismo sustentável, por sua vez, preza pela interação social com a geração de benefícios para a base comunitária.

Outros impactos negativos associados à implantação do hotel estão relacionados à ausência de participação comunitária no planejamento de algumas ações, principalmente naquelas que interferiram na vida de toda a comunidade, caso específico da praça construída e o despejo de esgoto sem tratamento, o que contribui para a degradação do manguezal.

Sem dúvida, houve um incremento na economia, porém sua instalação repercutiu negativamente em outros setores. O modelo de gestão adotado não contempla os critérios do turismo sustentável, que preza pela participação popular no processo de decisão, gerando benefícios socioeconômicos para todos os envolvidos com a atividade turística. De outro lado, o problema é acentuado com o acelerado e desordenado desenvolvimento do turismo na região, com a carência de políticas públicas que contemplem o planejamento do setor turístico na área.

O impacto ambiental negativo associado às dragagens e ao engordamento da praia refere-se à alteração da dinâmica e circulação costeira e das características bióticas e físico-químicas da área, promovendo prejuízos ao ecossistema marinho e ecossistemas 
associados a ele. $O$ engordamento é um processo paliativo para conter a erosão e existe a necessidade de manutenção da faixa da praia com dragagens periódicas e sistemáticas.

A paisagem característica do local sofreu alterações com a retirada de áreas de manguezais, remanescentes de Mata de Restinga e uma salina natural (utilizada como área de lazer), devido aos aterros feitos. Figura, hoje, uma paisagem artificial, com coqueiros anões adornando os arredores do empreendimento. A área destinada à construção dos condomínios, também foi desmatada e encontra-se ociosa.

A estrutura construída para receber os antigos moradores do terreno desapropriado apresentou falhas que interferem adversamente na comunidade. O sistema de saneamento básico ficou inacabado e o esgoto deságua em manguezal próximo, sem tratamento adequado; as casas ficaram em nível mais baixo em relação à via de acesso asfaltada; e a inexistência de obras de drenagem contribui para ocorrência de enchentes.

Atualmente, é difícil cobrar providências dos administradores, pois alegam que as estruturas implantadas foram construídas por antigos proprietários e que a venda do local não implicou no repasse das responsabilidades das obras. Tratou-se, porém, de uma compensação ambiental imposta aos empreendedores devido aos impactos ambientais ocasionados pelo equipamento. É sua obrigação corrigir as deficiências. Este é um ponto falho do processo, pois as exigências do órgão licenciador não são cumpridas e não existem fiscalização e monitoramento eficientes para cobrar as ações impostas.

Para a população, as casas recebidas representaram uma conquista perante a desapropriação. Acreditaram ser uma benfeitoria do hotel, no entanto, tratou-se de uma medida compensatória em razão da desapropriação. Sentiram-se muito bem com os imóveis, apesar das condições ruins de habitação, saneamento inacabado, ausência de aterro, abastecimento de água e energia, pois se comparadas às antigas moradias, são de qualidade superior. As antigas casas eram em sua maioria de taipa, algumas eram de alvenaria, com padrão de casa popular.

A pesca, principal atividade econômica, passava por um processo de declínio, em vista das mudanças ambientais ocasionadas pela instalação do Porto de Suape que acarretou a diminuição da produtividade. Em complemento à renda, existia o pequeno comércio e serviços de caráter informal, além da venda de frutos que serviam, também, para consumo próprio. Estavam presentes pequenos agricultores de subsistência e trabalhos da cana-de-açúcar.

O turismo, por sua vez, pôde dinamizar a economia, mas de modo bastante limitado, com incrementos no comércio e prestação de serviços. A problemática envolve a priorização do turismo como atividade econômica principal, sem oferecer alternativas de produção e renda para épocas de baixa estação.

A comunidade preocupa-se com os futuros investimentos que possam ser feitos, a exemplo dos loteamentos e da ampliação do Porto do Suape, que podem acarretar a vinda de mais pessoas e o aumento dos problemas existentes. Os maiores prejudicados foram os mais carentes que tinham como principal fonte de renda e de subsistência, a pesca manual. Possuíam, além disso, menor grau de instrução, impedindo-os de serem absorvidos pelo mercado de trabalho em ascensão.

A construção do empreendimento acarretou a destruição de áreas de vegetação 
Passivos socioambientais oriundos de empreendimentos turístico-hoteleiros e seus impactos na base comunitária

nativa e o aterro de trechos de mangue que serviam como fonte de renda e alimentação para a comunidade local. Os empreendedores, por sua vez, priorizaram os benefícios econômicos em relação aos aspectos ambientais e sociais e não planejaram ações social e ambientalmente responsáveis para o entorno.

\section{Considerações finais}

As análises focaram os passivos socioambientais gerados pelo empreendimento turístico-hoteleiro citado, em contraposição ao EIA encaminhado à $\mathrm{CPRH}$ para obtenção da licença ambiental. É preciso destacar o momento histórico em que foi elaborado, na década de 1990. Na época, as metodologias e técnicas para avaliação de impactos ambientais eram distintas do que vem sendo aplicado nos estudos atuais. A tendência é a evolução do processo ao longo do tempo, mas é preciso estar atento aos estudos outrora realizados, para que sirvam de base para reflexões e mudanças futuras. E, assim, promovam melhorias no processo de licenciamento como um todo, em especial, para empreendimentos do setor turístico-hoteleiro.

O estudo ressaltou algumas falhas do licenciamento e da AIA na prevenção de danos ambientais, a partir do principal instrumento utilizado em ambos os processos, o EIA. Percebeu-se que os preceitos da AIA e do licenciamento vêm sendo postos em prática na confecção dos estudos, porém enfatizam os benefícios econômicos. A conservação ambiental, entretanto, deve permear todos os aspectos relacionados aos empreendimentos, inclusive os de cunho econômico. Se essa condição não for cumprida com rigor e critério, ofuscará a credibilidade enquanto instrumentos de planejamento e de apoio à gestão ambiental, perante a sociedade.

Os passivos socioambientais, um dos aspectos limitantes da AIA, podem representar evidências disso, pois foram gerados a partir da implantação de determinadas ações antes mesmo do término do processo de licenciamento.

Os benefícios sociais não foram tão evidentes quanto apresentados no EIA. As condições de moradia evoluíram graças à compensação ambiental, paga pelos empreendedores com a construção de casas para os moradores. Porém, as obras de infraestrutura básica não foram concluídas o que se reflete, de forma negativa, na vida da população. A poluição ambiental cresce no entorno do empreendimento, com a contaminação dos manguezais por efluentes líquidos sem o devido tratamento.

Detalharam-se, ainda, outros problemas cruciais que interferem adversamente na conservação ambiental das áreas em questão: falta de pessoal nos órgãos ambientais para fiscalização; falta de programas de monitoramento ambiental; estruturas e equipamentos não condizentes com a realidade local; ineficiência na participação popular, sem a inserção dos diferentes atores sociais da comunidade local nas discussões e planejamento das ações; e parcialidade das equipes multidisciplinares, no sentido de apresentarem estudos favoráveis aos empreendimentos, sem reforçarem seus danos ambientais ou contestarem as superestruturas projetadas.

Foi possível perceber que o projeto preocupou-se com aspectos econômicos e políticos, apresentando conceitos ligados à conservação ambiental que, na prática, acarretariam a destruição dos recursos naturais. Além disso, o turismo é exaltado como o elemento dinamizador da economia, criando-se fortes laços de dependência. O ideal, entretanto, é a prática do turismo como uma complementação às outras atividades econômicas, sem 
que, para isso, sejam esquecidas as raízes culturais, sociais e econômicas do local.

Vale ressaltar ainda que o envolvimento da sociedade civil organizada, especial da base comunitária, é fundamental para cobrar e pressionar o poder público e a iniciativa privada para que respeitem as leis ambientais, coibindo a degradação dos recursos naturais. O poder de pressão de entidades organizadas em grande parte inibe ações irresponsáveis, visto que assumem o papel de agentes fiscalizadores.

\section{Referencias bibliográficas}

ABREU, D. Os llustres Hóspedes Verdes. Salvador: Casa da Qualidade, 2001.

BARBIERI, J.C. Gestão ambiental empresarial: conceitos, modelos e instrumentos. São Paulo: Saraiva, 2004.

BNB. PRODETUR/NE II - Objetivos. Promovendo o desenvolvimento sustentável do turismo. Histórico.

BRASIL. Lei no 10.165, de 27 de dezembro de 2000. Altera a Lei n. 6.938, de 31 de agosto de 1981, que dispõe sobre a Política Nacional do Meio Ambiental, seus fins e mecanismos de formulação e aplicação, e dá outras providências.

BRASIL. Lei no 11.771.

BRASIL. Resolução CONAMA no 237 de 19 de dezembro de 1997. Dispõe sobre a revisão dos procedimentos e critérios utilizados no licenciamento ambiental.

BRASIL. Resolução CONAMA no 001 de 23 de janeiro de 1986. Estabelece critérios básicos e diretrizes gerais para a elaboração da Avaliação de Impacto Ambiental.

CARNEIRO, B.M. A implantação de vias e o manejo de áreas protegidas na região do Jalapão: a rodovia TO 110 e o seu entorno. 2008. Dissertação (Mestrado em Ciências do Ambiente) - Universidade Federal do Tocantins, Palmas.

CASTELO BRANCO, G.V.; SPINELLI, M.S. Análise dos Impactos Turísticos Ocorridos na Vila de Suape Após a Instalação do Hotel Blue Tree Park Beach Resort: um Enfoque Sociocultural. 2004. 121 f. Trabalho de Conclusão de Curso (Bacharelado em Turismo) Núcleo de Hotelaria e Turismo, Universidade Federal de Pernambuco, Recife.

COSTA, S.S. Lixo mínimo: uma proposta ecológica para hotelaria. Rio de Janeiro: Ed. SENAC Nacional, 2004.

COUTINHO, M.F. Turismo e planejamento sustentável: Centro Turístico de Guadalupe. 2000. 100f. Trabalho de Conclusão de Curso (Curso de Graduação em Ciências Econômicas) - CCSA, UFPE, Recife.

FERREIRA, J.L. A variável ambiental como componente na classificação da qualidade dos serviços hoteleiros. 1999. Dissertação (Mestrado em Engenharia de Produção) - Departamento de Engenharia de Produção, UFSC, Florianópolis.

IBAMA. Avaliação de impacto ambiental: agentes sociais, procedimentos e ferramentas. Brasília: Instituto Brasileiro do Meio Ambiente e dos Recursos Naturais Renováveis, 1995.

JERONYMO, A.C.J. Deslocamentos de populações ribeirinhas e passivos sociais e passivos econômicos decorrentes de projetos de aproveitamentos hidrelétricos: a Usina Hidrelétrica de Tijuco Alto. 2007. Dissertação (Programa Interunidades de Pós-graduação em 
Passivos socioambientais oriundos de empreendimentos turístico-hoteleiros e seus impactos na base comunitária

Energia) - Universidade de São Paulo, São Paulo.

KIRK, D. Environmental management for hotels: a student's handbook. Oxford: Butterworth Heinemann, 1996.

PEGADAS ECOLÓGICAS. Accor apresenta programa de sustentabilidade. 12 de maio de 2012. Disponível em: http://pegadas-ecologicas.blogspot.com.br/2012/05/accor-apresenta -programa-de.html. Acesso: 28 de maio de 2012.

PIRES FILHO, I.A. Estudo de impacto ambiental (EIA) do complexo turístico enseada de Suape. Recife: Pires \& Filho Advogados Associados, 1990.

ROCHA, E. C.; CANTO, J.L.; PEREIRA, P.C. Avaliação de impactos ambientais nos países do Mercosul. Ambiente e Sociedade, vol. VIII, n. 2, jul./dez. 2005. Disponível em: http://www.scielo.br/pdf/asoc/v8n2/28609.pdf. Acesso: 10 nov. 2006.

SWARBROOKE, J. Turismo sustentável: conceitos e impacto ambiental. São Paulo: Aleph, 2000.

\section{Nota:}

O turismo é considerado, conforme estabelece a Lei Federal oํ 10.165 de 27/12/2000, uma atividade econômica com potencial poluidor pequeno e obriga aos equipamentos de grande porte obterem a licença ambiental. Segundo a Resolução CONAMA o 237, de 19/12/1997, estão obrigados a solicitar a licença os complexos turísticos e de lazer, inclusive parques temáticos e autódromos.

Thays Regina Rodrigues Pinho: Universidade Federal do Maranhão, São Luís, MA, Brasil

Email: thayspinho@hotmail.com

Link para o currículo Lattes: $\underline{\text { http://lattes.cnpq.br/6971545107452648 }}$

Ana Jéssica Corrêa Santos: Universidade Federal do Maranhão, São Luís, MA, Brasil Email: anajessica02@hotmail.com

Link para o currículo Lattes: http://lattes.cnpq.br/1112343233804474

Data de submissão: 28 de junho de 2012

Data de recebimento de correções: 14 de dezembro de 2012

Data do aceite: 14 de dezembro de 2012

Avaliado anonimamente 